\title{
A note on factored infinite series and trigonometric Fourier series
}

\author{
Hüseyin $\mathrm{BOR}^{1}$ \\ ${ }^{1}$ P.O. Box 121
}

May 23, 2020

\begin{abstract}
In this paper, we have proved two main theorems under more weaker conditions dealing with absolute weighted arithmetic mean summability factors of infinite series and trigonometric Fourier series. We have also obtained some new results for different absolute summability methods.
\end{abstract}

\section{Hosted file}

HBR-20-02.pdf available at https://authorea.com/users/159057/articles/453515-a-note-onfactored-infinite-series-and-trigonometric-fourier-series 